\title{
Ectopic tubal pregnancy with partial mole: a rare case
}

\section{Nanda Patil, Robina Mohamed Nazeer*, Jyoti Tele}

Department of Pathology, Krishna Institute of Medical Sciences, Karad, Maharashtra, India

Received: 23 January 2018

Accepted: 28 February 2018

\section{*Correspondence: \\ Dr. Robina Mohamed Nazeer, \\ E-mail: mnrobina@gmail.com}

Copyright: (c) the author(s), publisher and licensee Medip Academy. This is an open-access article distributed under the terms of the Creative Commons Attribution Non-Commercial License, which permits unrestricted non-commercial use, distribution, and reproduction in any medium, provided the original work is properly cited.

\begin{abstract}
Hydatidiform moles are abnormal gestations characterised by the presence of hydropic changes in the placental villi associated with circumferential trophoblastic proliferation. They arise due to abnormal fertilization. Molar gestation commonly develops within the uterus but presence of molar changes in ectopic pregnancy is extremely rare. Author present a rare case of ectopic molar pregnancy in fallopian tube in a 20 years old female patient to highlight its clinicopathological features. Ectopic molar pregnancy in a fallopian tube is very rare and histopathological study is the gold standard for the exact diagnosis and further management.
\end{abstract}

Keywords: Clinicopathological features, Ectopic mole, Tubal pregnancy

\section{INTRODUCTION}

Gestational trophoblastic disease includes a spectrum that consists of hydatidiform mole, invasive mole and nonmolar trophoblastic tumors which consists of placental site trophoblastic tumour and choriocarcinoma. The characteristic feature of this disease is raised Beta Human Chorionic Gonadotropin ( $\beta-\mathrm{HCG})$ levels which are useful for diagnosis as well as follow up after treatment and for prediction of recurrence.

Hydatidiform mole is the commonest gestational trophoblastic disease and the incidence is $0.1 \%$ amongst all pregnancies. ${ }^{1}$

Hydatidiform mole occurs due to malformation of placenta as a result of genetic aberration of the villous trophoblast. Molar pregnancy develops within the uterus and its presence at the site of ectopic pregnancy is very rare. $^{2}$

Diagnosis of molar pregnancy at the ectopic site is very difficult as there are no distinguishing clinical features.
Author present clinicopathological features of a rare case of ruptured tubal pregnancy with incomplete mole.

\section{CASE REPORT}

A 20 years old female patient presented to the obstetric outpatient department with complaints of pain in abdomen with 8 weeks amenorrhea. There was no history of use of oral contraceptives or irregular menses. Urine pregnancy test was positive. Her ultra-sonography of the pelvis showed mixed echogenic mass lesion in the right adnexal region.

Evidence of gestational sac with thick choriodecidual reaction was noted within the mass. Yolk sac and embryo could not be identified separately. Exudative fluid collection was noted around the gestational sac in the pouch of Douglas. Findings were suggestive of right tubal ectopic gestation with signs of rupture. Her beta HCG levels were 16,230 IU/ ml.

Exploratory laparotomy proceeded to right sided salpingectomy, as right fallopian tube revealed ectopic 
pregnancy with ampullary rupture. The products were sent for histopathological examination.

\section{Histopathological examination}

On gross examination, the right fallopian tube measured $4.5 \mathrm{~cm}$ in length was dilated and ruptured near fimbrial end. Lumen showed blood clots with grape like vesicles (Figure 1).

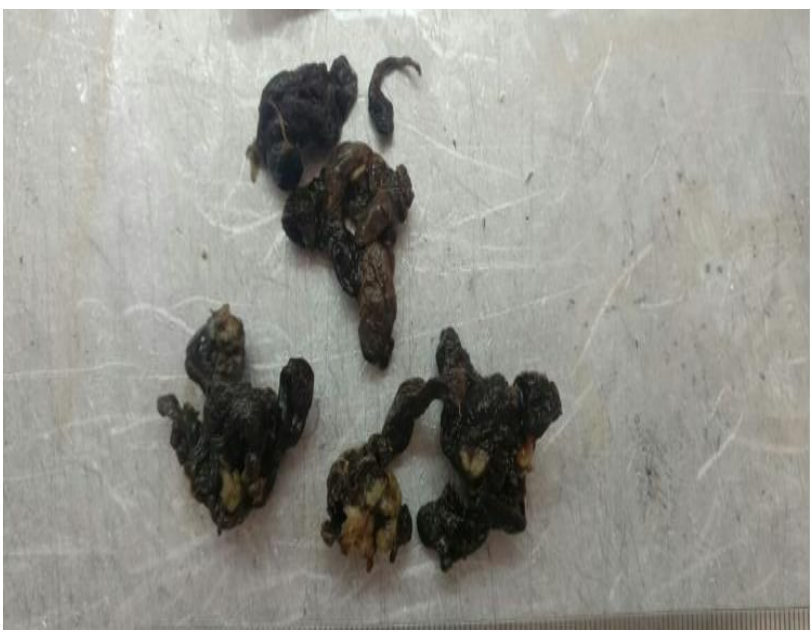

Figure 1: A ruptured tube with blood clots and grape like vesicles.

Microscopic examination revealed ruptured fallopian tube. The lumen contained blood clots with edematous avascular villi showing circumferential trophoblastic proliferation, mixed with few small sized villi (Figure 2 , 3).

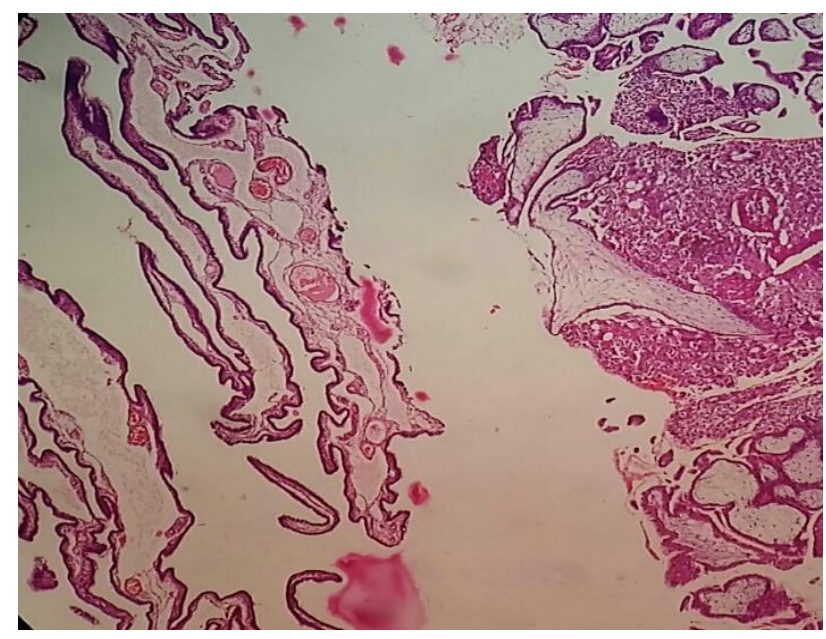

Figure 2: Microscopy- edematous avascular villi with circumferential trophoblastic proliferation along with small villi at fimbrial end. (100x H E).

Considering these features diagnosis was given as ruptured tubal ectopic pregnancy with incomplete hydatidiform mole.

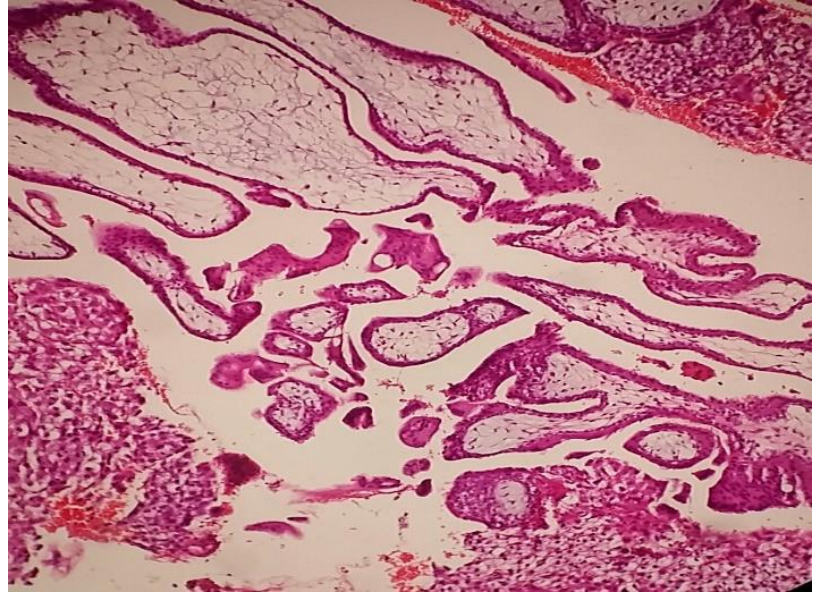

Figure 3: Microscopy- Enlarged avascular edematous villi along with small villi and trophoblast $(400 \times \mathrm{HE})$.

\section{DISCUSSION}

Hydatidiform moles are abnormal gestations characterized by hydropic changes involving some or all of the placental villi and circumferential proliferation of trophoblastic tissue. Risk of partial mole is associated with use of oral contraceptive and a history of irregular menstruation. ${ }^{3}$ Though no such history was available in our case.

Hydatidiform moles arise due to abnormal fertilization. Complete mole occurs when an empty ovum is fertilized by a haploid spermatozoan which duplicates afterwards or rarely by fertilization with two sperms. The chromosomal component is $46 \mathrm{XX}$ while a partial mole occurs with fertilization of two sperms with a haploid ovum resulting in a triploid genome. . $^{3-6}$

Molar pregnancy is seen in 1 in 500-1000 pregnancies. ${ }^{7}$ Molar pregnancy at an ectopic site is a rare occurence. Molar pregnancy should be distinguished by hydropic abortus as the former can lead to persistent trophoblastic disease.

The risk of persistent trophoblastic disease is of $0.5 \%$ for partial mole and $15 \%$ for complete mole. ${ }^{8}$ In our case the microscopic features were of incomplete hydatidiform mole. Another complication of ectopic molar pregnancy is metastasis to distant organs like lung. ${ }^{9,10}$ Hence close follow up is essential after removal of the products.

Although beta HCG levels are increased in tubal molar pregnancy, they are usually lower than the levels observed in a molar intrauterine pregnancy as a result of insufficient vascularization in the fallopian tube. ${ }^{11}$ Similar observation was found in our case.

The risk factors for ectopic pregnancy include pelvic inflammatory disease, tubal surgery, intrauterine contraceptive devices and previous ectopic pregnancy. Although $50-75 \%$ of cases reveal no obvious risk 
factors. ${ }^{12}$ In the present case also no such risk factors could be identified. Clinical features and laboratory tests are not sufficient for differentiation of tubal ectopic pregnancy from molar pregnancy in fallopian tube. But chances of rupture are high in tubal molar ectopic pregnancy. ${ }^{13}$

Similar findings were observed in our case. Molar pregnancy was not diagnosed clinically as well as with USG in our case.

Management of ectopic molar pregnancy is immediate surgical intervention and salpingectomy. ${ }^{14}$ As ectopic molar pregnancy is difficult to diagnose on clinical or radiological basis; histopathological examination is essential for the final diagnosis. $2-4 \%$ of patients with partial mole develop persistent tumour and require chemotherapy for remission. ${ }^{15}$ The case had remission after the surgery.

\section{CONCLUSION}

Ectopic molar pregnancy is a rare occurrence. It is important to consider the possibility of hydatidiform mole in the extra uterine site in patients with clinical presentation similar to ectopic pregnancy. For the correct diagnosis of ectopic molar pregnancy and its further management, histopathological examination of products of conception is very important.

Funding: No funding sources Conflict of interest: None declared

Ethical approval: Not required

\section{REFERENCES}

1. Moon HH, Kim SM, Moon JH, Kang WD, Choi HS. Metastatic gestational trophoblastic neoplasm presenting as spontaneous renal and cerebral hemorrhage with low titre of HCG; a case report of an unusual case. Korean J Obstet Gynecol. 2012;55(10):766-71.

2. Samaila MO, Adesiyun AG, Bifam C. Ruptured tubal hydatidiform mole. J Turkey- German Assoc. 2009; 10:172-4.

3. Burton JL, Lidbury EA, Gillespie AM, Tidy JA, Smith O, Lawry J. et al. Over diagnosis of hydatidiform mole in early tubal ectopic pregnancy. Histopathology. 2001;38:409-17.
4. Chauhan S, Diamond MP, Johns DA., A case of molar pregnancy. Fertil Steril. 2004,81(4):1140-1.

5. Jacobs PA, Szulman AE, Funkhouser J, Matsuura JS, Wilson CC., Human triploidy: relationship between parental origin of the additional haploid complement and development of partial hydatidiform mole. Ann Hum Genet. 1982;46:223-31.

6. Depypere HT, Dhont M, Verschraegen-Spae MR, Coppens M., Tubal hydatidiform mole. Am J Obstet Gynecol. 1992;169:209-10.

7. Sebire NJ, Lindsay I, Fisher RA, Savage P, Seckl MJ., Over diagnosis of complete and partial hydatidiform mole in tubal ectopic pregnancies. Int $\mathbf{J}$ Gynecol Path. 2005;24(3):260-4.

8. Seckl MJ, Fisher RA, Salerno G. et al., Choriocarcinoma and partial hydatidiform mole. Lancet. 2000;356:36-9.

9. Hertig AT Atlas of tumour pathology, section 9. Armed Forces Institute of Pathology. Washington, DC; $1956: 33$.

10. Govender NS, Goldstein DP. Metastatic tubal mole andcoexisting intrauterine pregnancy. Obstet Gynecol. 1977;49:67-9.

11. Emoto M, Sadamori R, Hachisuga T, Kawarabayashi T, Miyamoto S., Clinical usefulness of contrastenhanced color Doppler ultrasonography in invasive and noninvasive gestational trophoblastic diseases: a preliminary study. The Journal of Reproductive Medicine. 2011;56(5-6):224-34.

12. Tabandeh A, Besharat $M$. Fever after cervical ectopic pregnancy; a case report from Gorgan, Iran. Electronic Physician. 2014;6(4):944-6.

13. Leung F, Terzibachian JJ, Chung FB, Lassabe C, Knoepffler F, Maillet R, et al. Heterotopic ovarian hydatidiform mole. A case report. Gynecologie, Obstetrique Fertilite. 2009;37(9):749-51.

14. Vaishnav V.A, very rare case of heterotopic pregnancy in natural conception with ectopic pregnancy as partial mole! J Obstet Gynaecol India. 2014;64(6):433-5.

15. Berkowitz RS, Goldstein DP. Current management of gestational trophoblastic diseases. Gynecol. Oncol. 2009;112(3):654-62.

Cite this article as: Patil N, Nazeer RM, Tele J. Ectopic tubal pregnancy with partial mole: a rare case. Int J Reprod Contracept Obstet Gynecol 2018;7:1651-3. 